\title{
O Trabalho Experimental e o Ensino da Química na Perspectiva de Trabalho Científico: Um Percurso de Investigação-Acção no Estudo do Tema Reacções Químicas e Energia ${ }^{+}$
}

\author{
A NA CRISTINA FA LC ÃO *
}

$\mathrm{O}$ que se passa frequentemente a nível dos currícula actuais de Física e Química, nomeadamente no ensino secundário, em que se privilegia a apresentação de conceitos e Leis acompanhados de uma série de exercícios rotineiros, onde o trabalho experimental é o simples seguimento de uma "receita" pré-estabelecida, é desafiante para qualquer professor interessado em reflectir sobre todo este processo, em melhorar o seu próprio ensino e em desempenhar um papel activo no ensino da sua disciplina, face aos desafios que a Educação em Ciência lança aos professores.

O estudo levado a cabo tem dois objectivos fundamentais: Por um lado, pretende conceber, desenvolver e validar uma estratégia de ensino, no âmbito da utilização do trabalho experimental como trabatho científico no Ensino Secundário, visando conteúdos da Unidade Temática "Trocas de Energia em Reacções Químicas", $11^{\circ}$ ano de escolaridade, o que poderá levar os professores de Ciências a reflectir sobre como utilizam o trabalho experimental. Simultaneamente. pretende desenvolver um percurso de "investigação-acção" que contribua para o desenvolvimento académico e profissional da autora e possa vir a fomentar a reflexão de outros professores de Química/Ciências do Ensino Secundário sobre o seu ensino, no sentido de o melhorarem.

O objecto de estudo é o trabalho experimental numa perspectiva de trabalho científico, visando o desenvolvimento de competências, capacidades e atitudes, no ensino-aprendizagem da Química, no quadro do professor investigador do seu próprio ensino. Defendem-se propostas metodológicas epistemologicamente fundamentadas em quadros pós-positivistas, no âmbito da Nova Filosofia da Ciência, como alternativas válidas a práticas de ensino das Ciências, ainda dominantes e marcados pelo paradigma positivista.
Escolheu-se uma tarefa CTS, isto é que relacionasse a ciência, a tecnologia e a sociedade, em particular interfaces entre a primeira e a última. A alimentação, o valor energético dos alimentos e a sua determinação, a noz na região de Trás-os Montes e até a agricultura foram itens que convergiram para que a tarefa fosse: "Determinação da energia que se liberta na combustão de uma noz".

O percurso de ensino, neste estudo, de natureza ideográfica e do tipo qualitativo, foi dividido em três fases fundamentais. Na primeira fase, pré-operacional, houve uma introdução à unidade temática, seguindo-se uma contextualização e problematização do tema proposto, isto é, determinação do valor energético de uma noz. Ainda nesta fase, foi necessário os alunos planearem cuidadosamente um percurso experimental que permitisse chegar àquele objectivo. $\mathrm{Na}$ fase seguinte, operacional, a tarefa foi realizada pelos alunos de duas turmas distintas, distribuídos em equipas de trabalho, na Escola Secundária Emídio Garcia, em Bragança. De acordo com o planeamento de cada grupo os alunos realizaram então, as diferentes actividades. Após a realização da experiência, na fase pós-operacional, houve uma discussão intra e inter-grupos, onde se analisaram oralmente os resultados obtidos. Em seguida, fez-se uma reflexão crítica escrita de todo o trabalho: alunos e professor investigador. Aos alunos foi-lhes pedido que elaborassem, em casa, um relatório crítico individual. Finalmente, foi-lhes proposto responderem a três questões abertas relacionadas com a actividade, a metodologia e as dificuldades, numa ficha anónima de apreciação de todo o percurso experimental seguido. De todas as fases foram feitos registos áudio, das interacções verbais dos alunos.

Os resultados obtidos, corroboram a relevância da utilização do trabalho experimental numa pers- pectiva de trabalho científico, nas aulas de Ciências-Físico-Químicas através de estratégias explorando em particular a problematização/ contextualização, o planeamento, a aprendizagem cooperativa, o papel formativo do erro e a comunicação crítica.

Não se trata, naturalmente, de contemplar todos os aspectos em cada um dos trabalhos práticos que se realizem, mas de os ter em conta para os incorporar na medida do possível, sendo a questão essencial evitar que quase todas as práticas se reduzam ao simples seguimento por parte dos alunos de uma receita pré-estabelecida, sem nenhum problema para abordar, sem hipóteses para formular, sem permitir a possibilidade de discutir vários procedimentos, fazer previsões, desenvolver capacidades como espírito crítico e criatividade, realizar o trabalho de acordo com os seus procedimentos e discutir ideias e resultados com os outros grupos. Um laboratório escolar não é um laboratório de investigação científica nem se pretende que os alunos se considerem cientistas, o fundamental é que, de uma forma organizada, possam familiarizar-se com atitudes e metodologias científicas.

Deste modo, o trabalho dos professores, nomeadamente dos professores de Química/Ciências, passa por uma solução semelhante à dos alunos, isto é, implicação em tarefas abertas, criativas, na difusão de experiências inovadoras, nos intercâmbios entre grupos de professores, em resumo. num trabalho de investigação e inovação que pode transmitir à docência, ao mesmo tempo que à aprendizagem, todo o interesse de uma actividade científica. Mas não basta querer investigar o seu próprio ensino, é preciso saber como fazê-lo. Isto implicará todo um programa de formação dos professores, para que este modelo de aprendizagem das Ciências como actividade de investigação possa ser usado, criticado e portanto sujeito a melhoramentos. 
Defende-se, então, uma cultura de formação, em que se fomentem e apoiem percursos de pesquisa que promovam uma outra apropriação pelos professores das suas práticas, isto é que confiram sentido, unidade e coerência a factos, fenómenos e circunstâncias relativos ao ensino das Ciências, contribuindo para uma nova dinâmica de crescimento pessoal e profissional.

A perspectiva de trabalho experimental como trabalho científico usada, implica, também, uma outra maneira de estar dos alunos, nos processos de aquisição do conhecimento, nomeadamente, no facto de os alunos reconhecerem e assumirem o pluralismo metodológico como instrumento estratégico de apreensão do saber.

Apesar das limitações do estudo, por um lado inerentes à metodologia usada e por outro, as limitações características de um estudo de investigação-acção, como professora investigadora do meu próprio ensino, foi uma experiência enriquecedora.

\section{+ Dissertação de Mestrado em Ensino de Física e Química, apresentada em 1998. na Universidade de Aveiro por Ana Cristina Falcão, sob a orientação de António F. Cachapuz. \\ E-mail: nop00672@mail.telepac.pt}

\section{ALGUMAS REFERÊNCIAS USADAS NESTE TRABALHO:}

ALIS, J.C. Trabajos prácticos de Física e Química como problemas. Alambique, Didáctica de las Ciencias Experimentales, 5 (1995) 67-76.

BORGFORD, C.L. e SUMMERLIN, L.R. Chemical Activities, American Chemical Society, Washington, (1988) 83-84.

CACHAPUZ, A., ROCHA, J. e JESUS, H. Química e ambiente -como de um problema ambiental se constitui uma estratégia de ensino do conceito de reacção química- ensino básico. Boletim SPQ, 38 (1989) 61-63.
CACHAPUZ, A. O Ensino da Química na Perspectiva de Trabalho Científico: O Exemplo da Termodinâmica. Química Nova, 18 (1) (1994), 91-96.

CACHAPUZ, A. Uma investigação mais relevante para os professores. Noesis, (1995) 42-45.

GIL PÉREZ, D. Contribución de la história y de la filosofia de las ciencias al desarrollo de un modelo de enseñanza/aprendizaje como investigación. Enseñanza de las Ciencias, 11 (2) (1993) 197-212.

GIL PÉREZ, D. New trends on science education. Int. J. Sci. Educ., 18 (8) (1996) 889-901.

HODSON, D. Practical work in school science: Exploring some directions for change. Int. J. Sci. Educ., 18 (7) (1996) 753-754.

MARTINS, I. P. e CACHAPUZ, A. How do pupils perceive the concept of energy in chemical situations? School Science Review, 781(257) (1990) 83-85.

MCNIFF, J., Action Research- Principles and Practice, Macmillan Education Ltd., London (1988).

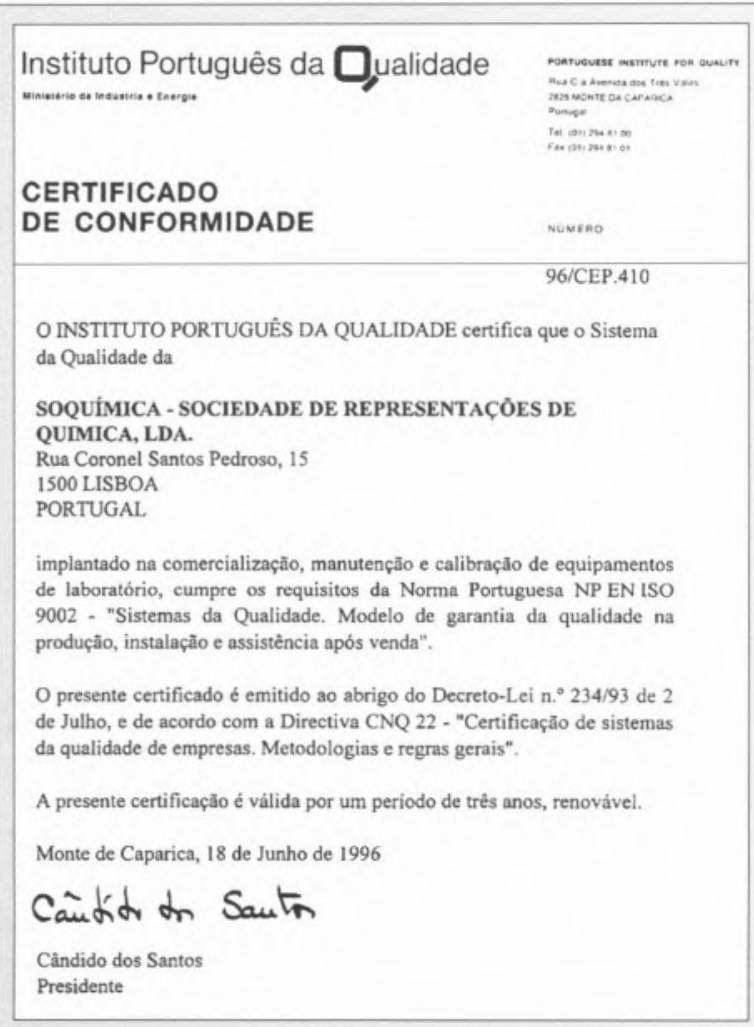

